\title{
Diverse water quality responses to extreme climate events: an introduction
}

\author{
Sujay S. Kaushal · Arthur J. Gold · Susana Bernal · Jennifer L. Tank
}

Published online: 20 November 2018

(C) Springer Nature Switzerland AG 2018

\begin{abstract}
We synthesize and summarize main findings from a special issue examining the origins, evolution, and resilience of diverse water quality responses to extreme climate events resulting from a Chapman Conference of the American Geophysical Union (AGU). Origins refer to sequences of interactive disturbances and antecedent conditions that influence diversification of water quality responses to extreme events. Evolution refers to the amplification, intensification, and persistence of water quality signals across space and time in watersheds. Resilience refers to strategies for managing and minimizing extreme water quality impacts and ecosystem recovery. The contributions of this special issue, taken together, highlight the following: (1) there is
\end{abstract}

\section{S. S. Kaushal $(\bowtie)$}

Department of Geology \& Earth System Science Interdisciplinary Center, University of Maryland, College Park, USA

e-mail:skaushal@umd.edu

\section{A. J. Gold}

Department of Natural Resources Science, University of Rhode Island, Kingston, USA

\section{S. Bernal}

Integrative Freshwater Ecology Group, Center for Advanced Studies of Blanes (CEAB-CSIC), Blanes, Girona, Spain

\section{J. L. Tank}

Department of Biological Sciences, University of Notre Dame, Notre Dame, USA diversification in the origins of water quality responses to extreme climate events based on the intensity, duration, and magnitude of the event mediated by previous historical conditions; (2) interactions between climate variability and watershed disturbances (e.g., channelization of river networks, land use change, and deforestation) amplify water quality 'pulses,' which can manifest as large changes in chemical concentrations and fluxes over relatively short time periods. In the context of the evolution of water quality responses, results highlight: (3) there are high intensity and long-term climate events, which can generate unique sequences in water quality, which have differential impacts on persistence of water quality problems and ecosystem recovery rates; and (4) 'chemical cocktails' or novel mixtures of elements and compounds are transported and transformed during extreme climate events. The main findings regarding resilience to extreme climate events are that: (5) river restoration strategies for reducing pollution from extreme events can be improved by preserving and restoring floodplains, wetlands, and oxbow ponds, which enhance hydrologic and biogeochemical retention, and lengthen the distribution of hydrologic residence times; and (6) the biogeochemical capacity for stream and river ecosystems to retain and transform pollution from landscapes can become "saturated" during floods unless watershed pollution sources are reduced. Finally, the unpredictable occurrence of extreme climate events argues for wider deployment of high-frequency, in situ sensors for 
monitoring, managing, and modeling diverse water quality responses. These sensors can be used to develop robust proxies for chemical cocktails, detect water quality violations following extreme climate events, and effectively trace the trajectory of water quality recovery in response to managing ecosystem resilience.

Keywords Extreme climate events .

Eutrophication $\cdot$ Ocean acidification $\cdot$ Salinization

\section{Diverse origins of water quality responses to extreme climate events}

In popular media, extreme climate events are often associated with a single, powerful driver-either short-term high energy events such as tropical cyclones (Lugo 2018; Paerl et al. 2018; Vidon et al. 2018) (Fig. 1), or prolonged changes in climatic conditions such as drought (Humphries and Baldwin 2003), warming or changes in atmospheric deposition (Groffman et al. 2018; Salisbury and Jönsson 2018). However, many of the papers in this special issue focus on unusual sequences of climatic events, each of which, individually, may occur with some regularity, that serve to amplify responses in aquatic biogeochemistry (McMillan et al. 2018) (Fig. 2). Such events include freeze-thaw episodes followed by intense winter storms (Inamdar et al. 2017), or a series of intense storms within a brief period of time (McMillan et al. 2018). Substantial climate-induced changes in water quality can also occur from less obvious drivers, such as a major insect defoliation event that was related to an intense drought in the preceding year (Addy et al. 2018), or a combination of warming and declining atmospheric nitrogen $(\mathrm{N})$ deposition leading to increased $\mathrm{N}$ uptake and decreased $\mathrm{N}$ export from forested catchments (Groffman et al. 2018) (Fig. 2).

The studies included in this special issue also show that water quality responses to extreme climate events are shaped by interactions between geology, topography, and land use, and their magnitude varies among climatic zones (Kaushal et al. 2018a). In fact, interactions between climate variability and watershed disturbances (e.g., channelization of river networks, land use change, and deforestation) amplify and intensify water quality 'pulses,' which manifest as large changes in chemical concentrations and fluxes over relatively short time periods (Kaushal et al. 2008, 2014, 2017). Human-dominated land use not

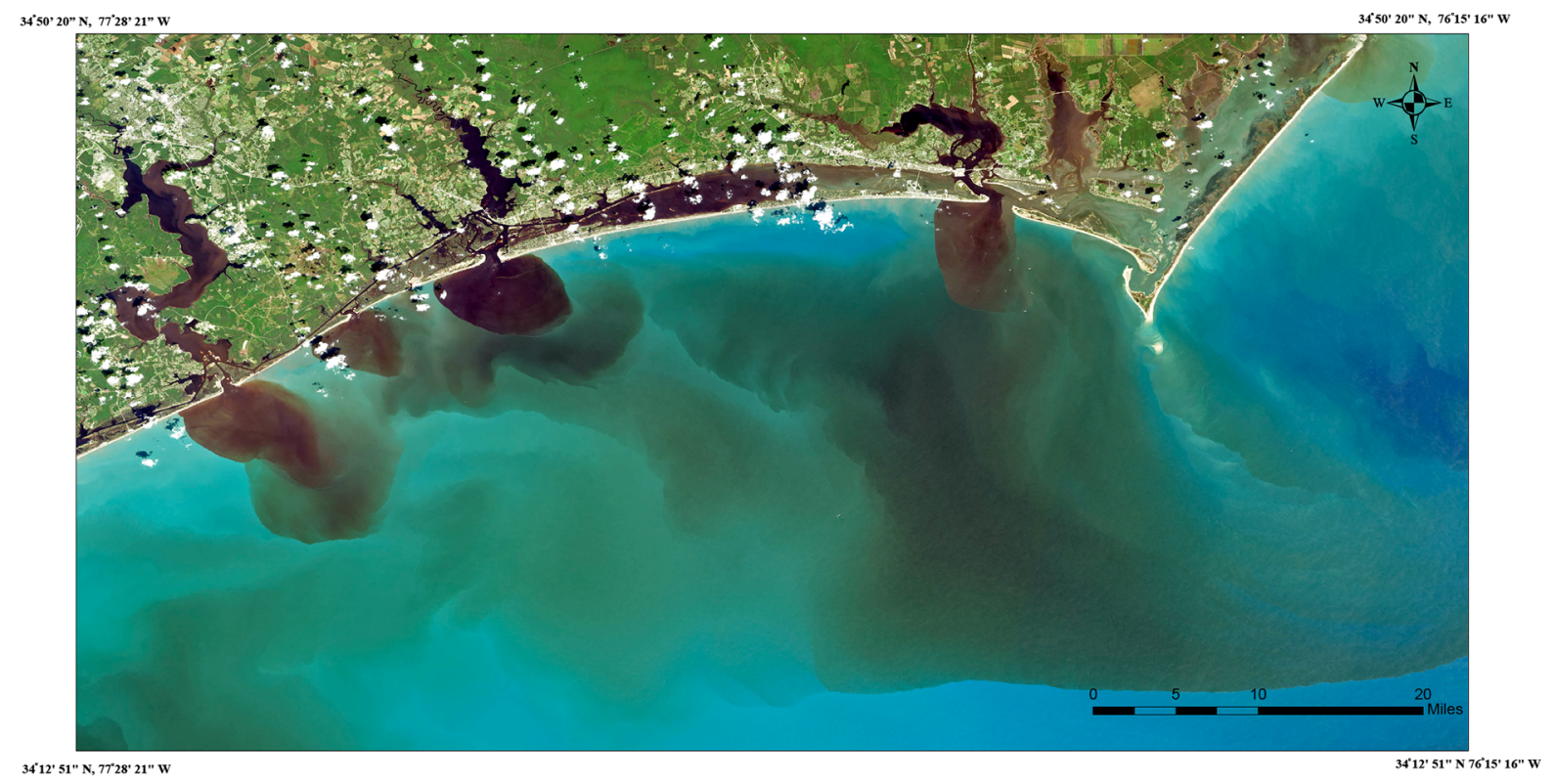

Fig. 1 Water quality degradation along the North Carolina coast on September 20, 2018 from flood waters in White Oak River, New River, Adams Creek, and their outflows following
Hurricane Florence. Natural color image from Landsat 8. Credit: Joshua Stevens/U.S. Geological Survey/NASA 


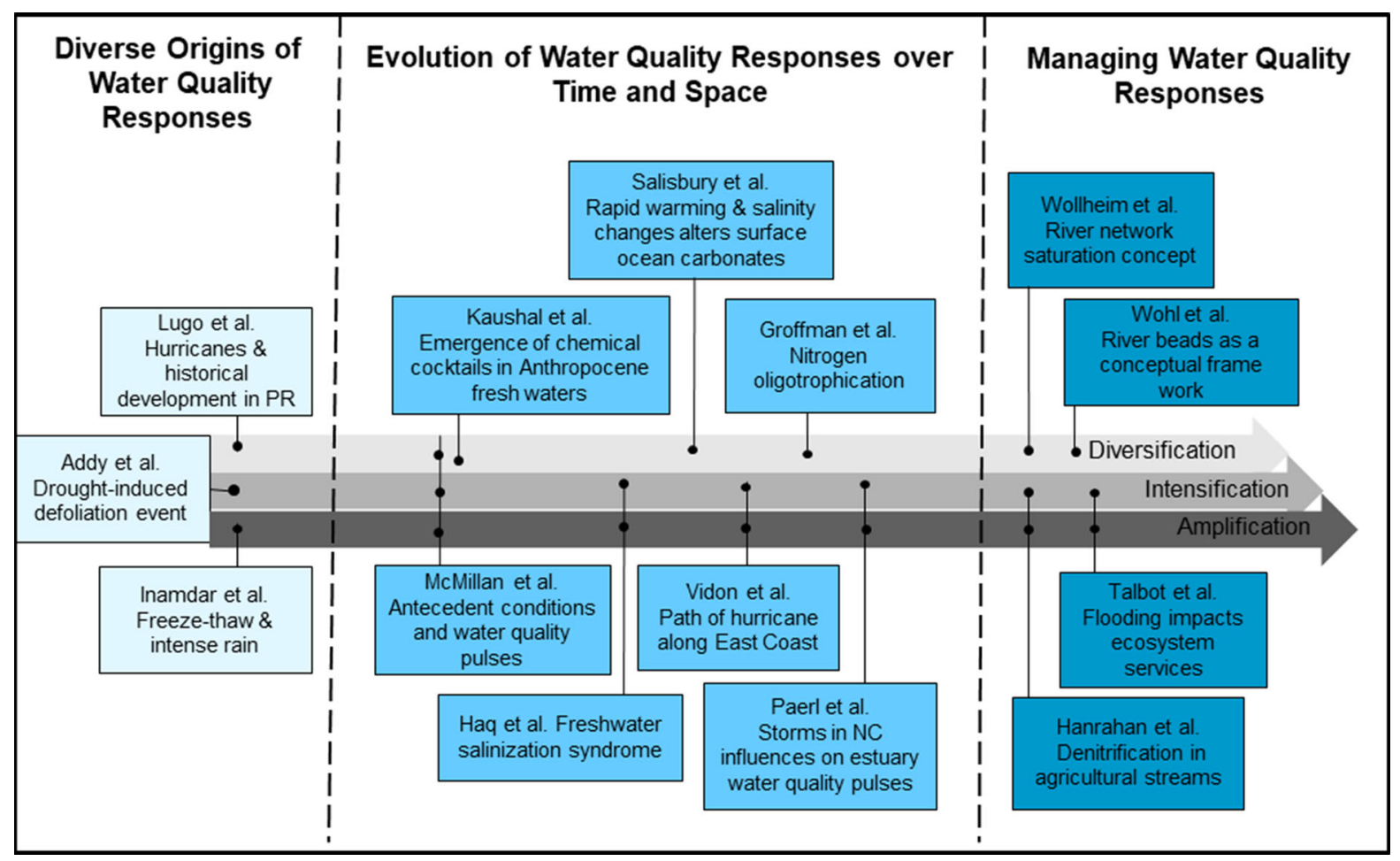

Fig. 2 Schematic representation of how contributions in this Special Issue can inform our understanding of origins, evolution, and managing water quality responses and ecosystem resilience in response to extreme climate events

only amplifies water quality pulses, but also gives rise to formation of novel chemical mixtures and combinations of water quality constituents. These novel "chemical cocktails" arise from complex interactions between land use and climate, and can provide a conceptual framework for grouping formation, transport, and transformation of elements in watersheds throughout extreme climate events (Kaushal et al. 2018a). Together, the studies compiled in this special issue highlight that the origins of water quality responses to extreme climate events are more complex than one might initially expect (Fig. 2), and that responses depend on past environmental conditions, and evolve differently in regards to amplification, intensification, and persistence depending on land use/land cover, geology, topography, and anthropogenic pressures (Fig. 2).

\section{Linking extreme climate events with the evolution of water quality responses over time and space}

The evolution of diverse water quality responses to extreme climate events resonates across varying spatial and temporal scales, depending on the energy, expansion, and duration of climate alterations. For example, there is a diversity of water quality responses based on the intensity, duration, and magnitude of the event combined with the context of previous historical conditions (Fig. 3). High intensity events such as tropical cyclones usually lead to pulse responses in water quality, with large changes in chemical concentrations and fluxes occurring over relatively short time periods (Fig. 1). Vidon et al. (2018) illustrates that Hurricane Irene and Tropical Storm Lee led to unprecedented increases in concentrations and loads of total suspended solids (TSS), particulate organic carbon (POC), and dissolved organic carbon (DOC) as these events moved through Maryland and Pennsylvania. Paerl et al. (2018) also shows a large impact of high runoff tropical cyclones on annual $\mathrm{N}$ and phosphorus (P) fluxes. Yet, the impact of hurricanes 
Fig. 3 Interactions between origins and types of extreme climate events interact with land use and antecedent conditions to amplify, intensify, and/or diversify water quality responses. High-intensity versus low-intensity events contribute to either pulses in water quality or long-term trends pressure responses, which can both be managed by regulating hydrology, reducing chemical inputs, and enhancing

biogeochemical functions in watersheds and drainage waters. The black squares below each colored rectangle refer to specific examples developed in the studies included in this Special Issue

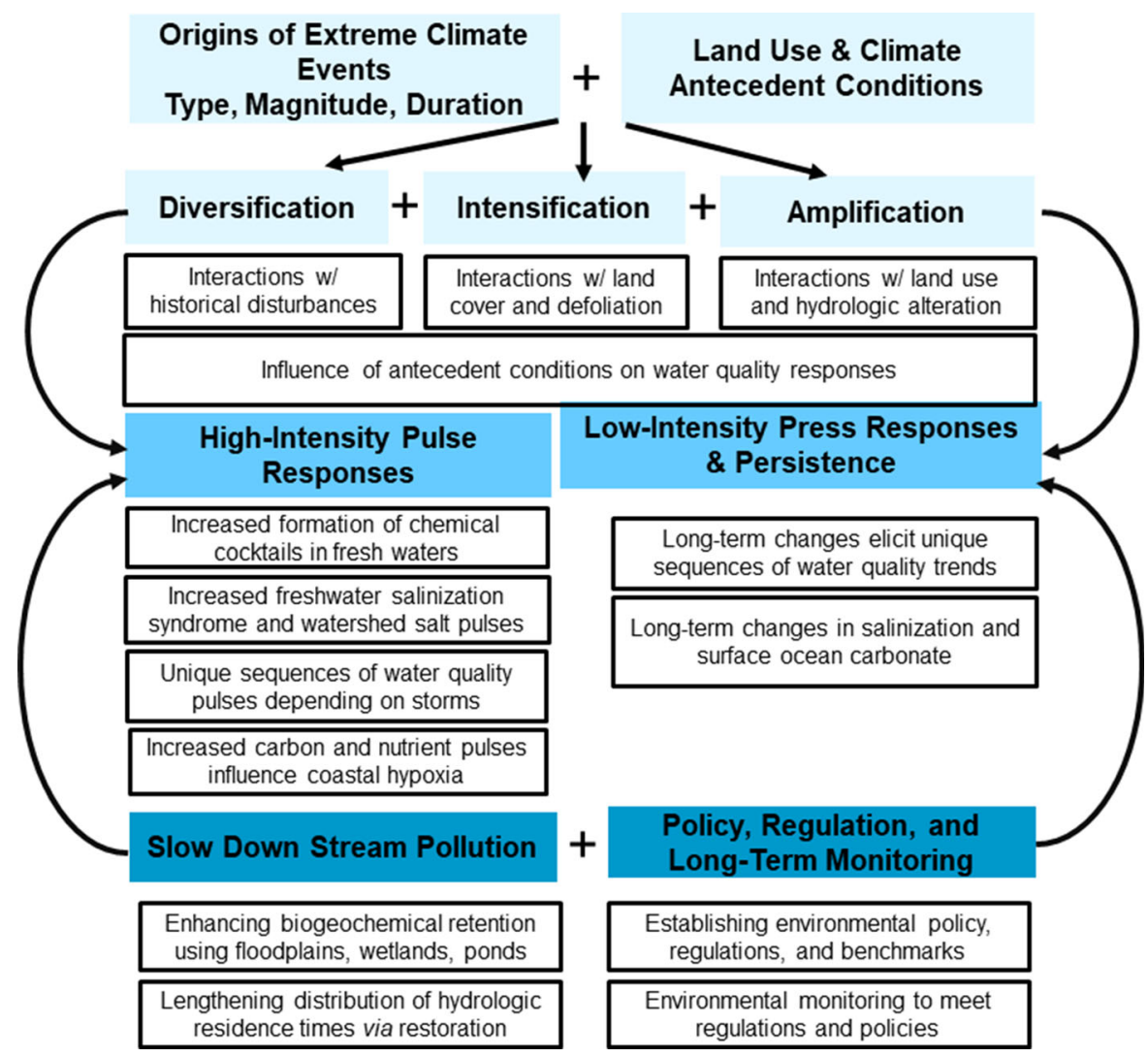

on carbon (C) fluxes varied depending on wind energy; high wind, low runoff hurricanes enhanced $\mathrm{CO}_{2}$ emissions from $\mathrm{C}$ stores in estuaries, while high runoff hurricanes mobilized and transported terrestrial-derived $\mathrm{C}$ to estuaries (Fig. 1).

Long-term, low-intensity events such as warming climate or changes in atmospheric deposition also impact water quality, with biological and geochemical responses that are sustained over time, and thus, can be defined more as press responses than as pulse responses (Lake 2000). Salisbury and Jönsson (2018) found that an extreme, decadal warming event in the Gulf of Maine, led to marked alterations in the carbonate system of the sea surface waters. The warming, combined with increases in sea surface salinity, mitigated the effects of ocean acidification, with consequences for calcifying organisms. Their study highlights the importance of varying temporal scales on regional processes for controlling $\mathrm{CO}_{2}$. Groffman et al. (2018) showed that sustained declines in $\mathrm{N}$ atmospheric deposition combined with warming can lead to unexpected declines in $\mathrm{N}$ export in temperate forests as a consequence of complex interactions between ecosystem $\mathrm{C}$ and $\mathrm{N}$ cycles.

Unusual combinations of climatic events can also generate extreme responses in water quality (Fig. 3). Both high-intensity and long-term, low-intensity events can generate sets of drivers that differ in their impacts on the persistence of water quality problems, as well as ecosystem recovery rates. For example, Inamdar et al. (2017) found that freeze-thaw episodes, followed by winter rainstorms, exported pulses of sediment, particulate organic carbon and particulate nitrogen, at levels that were comparable to single, high-energy tropical storm events. Sediment pulses were likely derived from stream bank erosion and channel storage, which were mobilized and then transported in streams by the combination of events. Given predictions of future climate that suggest high variability in winter temperatures, streams with legacy sediment deposits may be particularly vulnerable to this type of climatic driver, augmenting the risk of water quality degradation in downstream receiving waters. 
In another unexpected combination, Addy et al. (2018), report on a severe drought that created conditions favorable for a defoliation event in a forested catchment. The lack of riparian shade, coupled with inputs of nutrients from frass and leaf detritus, was associated with increased stream temperatures, decreased oxygen levels, and resultant changes in stream metabolism. Finally, the interaction between long-term low-intensity events such as climate change, pollution, and land use change has enhanced transport of chemical cocktails of carbon, nutrients, salts, and metals in freshwaters over the past 100 years (Kaushal et al. 2018a). From the perspective of high-intensity events, there can be distinct sequences in the formation, transport, and transformation of different chemical cocktail pulses during storms based on watershed sources, particle sizes and charges, chemical mobility, and bioreactivity (Kaushal et al. 2018a). For example, Haq et al. (2018) show that snowstorms can produce episodic salinization of freshwaters and trigger mobilization of different chemical cocktails of carbon, nutrients, and major ions from sediments to streams contributing to the Freshwater Salinization Syndrome (sensu Kaushal et al. 2018b, c).

\section{Resilience of water quality to extreme climate events}

Extreme climate events not only influence the magnitude, persistence, and sequence of water quality responses, but they can also influence the trajectories of ecosystem resilience and recovery. Management strategies can be developed and improved when there is good predictive understanding of the specific chemical responses and consequences from highintensity versus long-term climate impacts (Fig. 3). For example, high-frequency, low-intensity floods enhance many ecosystem services while low-frequency, high-intensity floods generate losses in ecosystem services (Talbot et al. 2018). River restoration strategies for reducing pollution from extreme events can be improved by identifying features along drainage networks such as floodplains, wetlands, oxbow ponds, and reservoirs, which enhance hydrologic retention, and lengthen the distribution of hydrologic residence times (Wohl et al. 2017; Wollheim et al. 2018). For example, the restoration of floodplains in agricultural waterways can increase hydrologic residence times during floods and enhance $\mathrm{N}$ removal via denitrification (Hanrahan et al. 2018). The extent of floodplain conservation and/or restoration in a watershed may be critical for the potential to mitigate water quality pulses in streams as the intensity of hydrologic events increases.

The effects of extreme climate events on downstream estuaries are also challenging to anticipate; freshwater inputs and rapid flushing rates can modulate phytoplankton communities and abundance (Paerl et al. 2018). While extreme storms can mobilize sediment, carbon, and nutrient pulses to estuaries, the increase in water fluxes may alter hydrologic residence times, which can also influence eutrophication and hypoxia. Therefore, nutrient management strategies for estuarine receiving waters must consider both amplification of watershed pulses of chemicals and their dynamics (Paerl et al. 2018).

\section{Future directions}

Many studies included in this special issue highlight the need to improve our mechanistic understanding of water quality responses to extreme events, particularly if we are to minimize and mitigate their impact on aquatic ecosystems (Fig. 2). Water quality information related to the timing, magnitude, and recurrence of extreme climate events is limited, due to the challenge in anticipating the occurrence of extreme climate events, and the time-lag associated with deploying monitoring instrumentation. As such, in situ high-frequency sensors will play a critical role in continuous monitoring of hydrological and physicochemical variables before, during, and after extreme events.

New optical sensors provide an array of highfrequency data sets and information that is critical in developing proxies for monitoring complex chemical cocktails, tracking their trajectory over time in response to extreme weather events (Kaushal et al. 2018a). As high frequency monitoring becomes widespread across climatic regions, new data sets will likely reveal insights regarding the diverse origins and responses in water quality to extreme climate events. Therefore, there is a need to define appropriate chemical proxies (Haq et al. 2018; Kaushal et al. 2018a), design efficient sampling strategies 
(Wollheim et al. 2018; Vidon et al. 2018), and establish effective monitoring protocols (Vidon et al. 2018) in order to obtain high quality data that will be comparable among sites, in order to evaluate the response and recovery of aquatic ecosystems to extreme climate events across broader spatiotemporal scales.

Moreover, new conceptual and mathematical frameworks are needed that explicitly consider the occurrence of extreme climate events and their influence on biogeochemical fluxes in aquatic ecosystems, such as the Chemical Cocktail concept (Kaushal et al. 2018a) and the River Network Saturation Concept (Wollheim et al. 2018) included in this special issue. There is also a need to move beyond single contaminants towards an understanding of the dynamics of multiple chemical mixtures, and grouped transport of elements and compounds, as well as the dynamics of why, when, and where they are linked (Kaushal et al. 2018a, c).

Key questions remain regarding how long water quality alterations persist after extreme climate events, and how far they are transported along river networks and estuaries, before retention and transformation capacity is biologically and geochemically saturated. In addition to in situ sensors, remote sensing approaches using satellite imagery offers a unique perspective for tracking plumes of sediments, nutrients, and other contaminants from watersheds following extreme events (Fig. 1). In the future, using remote sensing imagery to characterize the timing of the 'plume to bloom' sequences at the mouths of rivers may be used as an index for tracking ecosystem resilience to extreme climate events among different watersheds, estuaries, and receiving waters. Integration of suites of sensors, along with remote sensing approaches, represents a research frontier that will enhance high-resolution monitoring, modeling, and management of extreme climatic events and their water-quality impacts across space and time spanning from headwaters to receiving waters.

Acknowledgements We thank Shreeram Inamdar and the program committee for organizing the AGU Chapman Conference. We thank all of the authors and reviewers for their contributions to this special issue. Kate Lajtha provided editorial support and encouragement.

\section{References}

Addy K, Gold AJ, Loffredo JA, Schroth AW, Inamdar SP, Bowden WB, Kellogg DQ, François Birgand (2018) Stream response to an extreme drought-induced defoliation event. Biogeochemistry 140(2):199-215

Groffman PM, Driscoll CT, Durán J, Campbell JL, Christenson LM, Fahey TJ, Fisk MC, Fuss C, Likens GE, Lovett G, Rustad L, Templer PH (2018) Nitrogen oligotrophication in northern hardwood forests. Biogeochemistry. https://doi. org/10.1007/s10533-018-0445-y

Hanrahan BR, Tank JL, Dee MM, Trentman MT, Berg EM, McMillan SK (2018) Restored floodplains enhance denitrification compared to naturalized floodplains in agricultural streams. Biogeochemistry. https://doi.org/10.1007/ s10533-018-0431-4

Haq S, Kaushal SS, Duan S (2018) Episodic salinization and freshwater salinization syndrome mobilize base cations, carbon, and nutrients to streams across urban regions. Biogeochemistry. https://doi.org/10.1007/s10533-0180514-2

Humphries P, Baldwin DS (2003) Drought and aquatic ecosystems: an introduction. Freshw Biol. https://doi.org/ 10.1046/j.1365-2427.2003.01092.x

Inamdar S, Johnson E, Rowland R, Warner D, Walter R, Merritts D (2017) Freeze-thaw processes and intense rainfall: the one-two punch for high sediment and nutrient loads from mid-Atlantic watersheds. Biogeochemistry. https:// doi.org/10.1007/s10533-017-0417-7

Kaushal SS, Groffman PM, Band LE, Shields CA, Morgan RP, Palmer MA, Belt KT, Fisher GT, Swan CM, Findlay SEG (2008) Interaction between urbanization and climate variability amplifies watershed nitrate export in Maryland. Environ Sci Technol 42:5872-5878. https://doi.org/10. 1021/es800264f

Kaushal SS, Mayer PM, Vidon P, Smith RM, Pennino MJ, Duan SW, Newcomer TA, Welty C, Belt KT (2014) Land use and climate variability amplify carbon, nutrient, and contaminant pulses: a review with management implications. J Am Water Resour Assoc. https://doi.org/10.1111/jawr.12204

Kaushal SS, Gold AJ, Mayer PM (2017) Land use, climate, and water resources-global stages of interaction. Water 9:815

Kaushal SS, Gold AJ, Bernal S, Newcomer-Johnson TA, Addy K, Burgin A, Burns DA, Coble AA, Hood E, Lu Y, Mayer P, Mayer P, Minor EC, Schroth AW, Vidon P, Wilson H, Xenopoulos MA, Doody T, Galella JG, Goodling P, Haviland K, Haq S, Wessell, Wood KL, Jaworski N, Belt KT (2018a) Watershed 'chemical cocktails': forming novel elemental combinations in Anthropocene fresh waters. Biogeochemistry. https://doi.org/10.1007/s10533-0180502-6

Kaushal SS, Likens GE, Pace ML, Utz R, Haq S, Gorman J, Grese M (2018b) Freshwater salinization syndrome on a continental scale. Proc Natl Acad Sci USA. https://doi.org/ 10.1073/pnas.1711234115

Kaushal SS, Likens GE, Pace ML, Haq S, Wood KL, Galella JG, Morel C, Doody TR, Wessel B, Kortelainen P, Raike A, Skinner V, Utz R, Jaworski N (2018c) Novel chemical cocktails in inland waters are a consequence of the 
freshwater salinization syndrome. Philos Trans R Soc-B. https://doi.org/10.1098/rstb.2018.0017

Lake PS (2000) Disturbance, patchiness and diversity in streams. J North Am Benthol Soc 19:573-592

Lugo AE (2018) Characterization of ten extreme disturbance events in the context of social and ecological systems. Biogeochemistry. https://doi.org/10.1007/s10533-0180453-y

McMillan SK, Wilson HF, Tague CL, Hanes DM, Inamdar S, Karwan DL, Loecke T, Morrison J, Murphy SF, Vidon P (2018) Before the storm: antecedent conditions as regulators of hydrologic and biogeochemical response to extreme climate events. Biogeochemistry. https://doi.org/10.1007/ s10533-018-0482-6

Paerl HW, Crosswell JR, Van Dam B, Hall NS, Rossignol KL, Osburn CL, Hounshell AG, Sloup RS, Harding LW Jr. (2018) Two decades of tropical cyclone impacts on North Carolina's estuarine carbon, nutrient and phytoplankton dynamics: implications for biogeochemical cycling and water quality in a stormier world. Biogeochemistry. https:// doi.org/10.1007/s10533-018-0438-x

Salisbury JE, Jönsson BF (2018) Rapid warming and salinity changes in the Gulf of Maine alter surface ocean carbonate parameters and hide ocean acidification. Biogeochemistry. https://doi.org/10.1007/s10533-018-0505-3
Talbot CJ, Bennett EM, Cassell K, Hanes DM, Minor EC, Paerl $\mathrm{H}$, Raymond PA, Vargas R, Vidon PG, Wollheim W, Xenopoulos MA (2018) The impact of flooding on aquatic ecosystem services. Biogeochemistry. https://doi.org/10. 1007/s10533-018-0449-7

Vidon P, Karwan DL, Andres SA, Inamdar S, Kaushal S, Morrison J, Mullaney J, Ross DS, Schroth AW, Shanley JB, Yoon B (2018) In the path of the Hurricane: impact of Hurricane Irene and Tropical Storm Lee on watershed hydrology and biogeochemistry from North Carolina to Maine, USA. Biogeochemistry. https://doi.org/10.1007/ s10533-018-0423-4

Wohl E, Lininger KB, Scott DN (2017) River beads as a conceptual framework for building carbon storage and resilience to extreme climate events into river management. Biogeochemistry. https://doi.org/10.1007/s10533-0170397-7

Wollheim WM, Bernal S, Burns DA, Czuba JA, Driscoll CT, Hansen AT, Hensley RT, Hosen JD, Inamdar S, Kaushal SS, LE Koenig, Lu YH, Marzadr A, Raymond PA, Scott D, Stewart RJ, Vidon PG, Wohl E (2018) River network saturation concept: factors influencing the balance of biogeochemical supply and demand of river networks. Biogeochemistry. https://doi.org/10.1007/s10533-0180488-0 